\title{
Desenvolvimento regional: uma análise sobre a estrutura de um consórcio intermunicipal
}

\author{
Thiago Reis Xavier \\ Universidade Federal de Santa Maria (UFSM) \\ Milton Luiz Wittmann \\ Universidade Federal de Santa Maria (UFSM) \\ Raoni de Oliveira Inácio \\ Universidade Federal de Santa Maria (UFSM) \\ Juliana Kern \\ Universidade Federal de Santa Maria (UFSM)
}

\begin{abstract}
O desenvolvimento regional compreende um esforço das sociedades locais na formulação de políticas regionais com o intuito de discutir as questões que tornem a região sujeito de seu processo de desenvolvimento. O presente trabalho tem como objetivo descrever, por meio da análise da estrutura de governança, como o Consórcio de Desenvolvimento Sustentável da Quarta Colônia (Condesus) promove a articulação dos municípios da Quarta Colônia em prol do desenvolvimento regional. Para tal, realiza-se uma pesquisa qualitativa, de natureza exploratória descritiva e delineamento de estudo de caso. Como resultados, obteve-se que o Condesus representa um caso no qual predomina a administração pública, constituindo uma associação pública de direito privado, cuja estrutura administrativa é composta pela Presidência; Conselho de Prefeitos e Secretaria Executiva. O mesmo desenvolve projetos focados no desenvolvimento da Quarta Colônia, a partir do cooperativismo municipal. Conhecer a estrutura de governança do Condesus possibilita entender uma dinâmica original mediante a qual se espera compreender o processo de desenvolvimento regional.
\end{abstract}

Palavras-chave: desenvolvimento regional; governança; administração pública; consórcio; Condesus.

Desarrollo regional: un análisis de la estructura de un consorcio entre municipios

El desarrollo regional comprende un esfuerzo de las sociedades locales en la formulación de las políticas con el fin de debatir las cuestiones que hacen la región el sujeto pincipal en su proceso de desarrollo. Em este artículo se pretende describir como el consorcio para el desarrollo sostenible de la Cuarta Colonia

Artigo recebido em 27 ago. 2012 e aceito em 16 abr. 2013. 
(Condesus) promueve la articulación de los municipios en favor del desarrollo regional. Para tanto, se realiza una investigación cualitativa, de naturaleza exploratoria-descritiva y con bosquejo del método estudio de caso. Como resultado, se obtuvo que en el Condesus es una asociación publica de derecho privado, cuya estructura administrativa está compuesta por la Presidencia; El Consejo de intendetes y la Secretaría Ejecutiva; y que el mismo desarrolla proyectos enfocados en el desarrollo de la Cuarta Colonia, a partir de las cooperativas municipales. Conocer la estructura de gobernanza del Condesus posibilita el ententimiento de una dinámica original por medio de la cual se espera comprender el proceso de desarrollo regional.

Palabras clave: desarrollo regional; gobernanza; administración pública; consorcio; Condesus.

\section{Regional development: an analysis about the structure of a consortium of municipalities}

The regional development comprises an effort of local societies in the formulation of regional policies in order to discuss the issues that make the region responsible for its development process. This paper aims to describe, through the analysis of the governance structure, how the Consortium for Sustainable Development of Quarta Colônia (Condesus) promotes the coordination of the cities for regional development. For this, it was developed a qualitative research, with an exploratory and descriptive nature, and the design of a case study. As the result, it was found that the Condesus represents a case in which predominates the public administration, constituting a public association of private law, whose administrative structure consists in the Presidency, Council of Mayors and Executive Secretariat, and develops projects focused on the development of the Quarta Colônia, from the municipal cooperativism. Knowing the governance structure of Condesus, is possible to understand the original dynamics by which is expected to understand the regional development process.

Keywords: regional development; governance; public administration; consortium; Condesus.

\section{Introdução}

Os estudos envolvendo o desenvolvimento regional vêm ganhando relevância desde os anos 1990, em decorrência de uma estratégia europeia que visa reforçar programas de descentralização econômica regional, a partir da valorização das potencialidades endógenas (Tapia, 2005). Essa estratégia trouxe como consequência mudanças nas estruturas das redes informacionais de produção, distribuição e consumo. Além do incremento de sistemas econômicos localizados, a exemplo de sistemas locais de produção e governança de cadeias produtivas.

Partindo desse contexto, passa-se a compreender o desenvolvimento regional não apenas atrelado ao crescimento econômico, mas também a fatores sociais, culturais, ambientais e políticos, acompanhado da melhoria na qualidade de vida (Oliveira, 2002). Tais premissas podem ser salientadas por meio de análises que possibilitem a inclusão das alterações da composição da sociedade e da alocação de recursos pelos diferentes setores da economia, de forma a melhorar os indicadores de bem-estar econômico e social (pobreza, desemprego, desigualdade, condições de saúde, alimentação, educação e moradia) (Vasconcellos e Garcia, 1998). 
Sob uma percepção mais ampla acerca do tema em epígrafe, considera-se que, nos processos endógenos de desenvolvimento regional, são os atores da própria localidade que, ao adotarem estratégias, a partir do potencial desenvolvimentista existente em seu território, controlam o processo de transformação local visando aumentar o bem-estar da comunidade da qual fazem parte (Vázquez Barquero, 2001). O que leva à percepção de que o conjunto de recursos econômicos, humanos, institucionais e culturais regionais constitui o ponto de partida para o desenvolvimento de uma comunidade territorialmente localizada.

No entanto, faz-se necessário lembrar que, para promover o desenvolvimento, os planos regionais necessitam estar relacionados a estruturas de governança regional, resultantes da ação coletiva dos atores públicos e privados que interagem dentro de um contexto espacial, institucional, político e cultural específico (Tapia, 2005).

O termo governança regional refere-se às iniciativas ou ações que expressam a "capacidade de uma sociedade organizada territorialmente, para gerir os assuntos públicos a partir do envolvimento conjunto e cooperativo dos atores sociais, econômicos e institucionais" (Dallabrida, 2000:46), dentre as quais se podem citar: os fóruns ou conselhos regionais de desenvolvimento, as agências ou consórcios de desenvolvimento local ou regional, os grupos de interesse e as associações.

No Brasil, um caso no qual se observa a ocorrência de políticas de desenvolvimento regional por meio da articulação dos atores regionais através de um plano de governança territorial pode ser observado na Quarta Colônia no Rio Grande do Sul, cuja região encontra-se localizada no centro-oeste do estado (Xavier, 2012).

Na Quarta Colônia, há evidências sobre a existência de ações compartilhadas entre os municípios: Agudo, Dona Francisca, Faxinal do Soturno, Ivorá, Nova Palma, Pinhal Grande, Restinga Seca, São João do Polêsine e Silveira Martins. Este compartilhamento de ações torna-se possível devido às características geográficas e culturais locais que favorecem a busca por estratégias conjuntas capazes de minimizar as precariedades e maximizar as potencialidades da região (Xavier, 2012).

Todavia, mesmo diante dessas potencialidades locais, por muito tempo notou-se na Quarta Colônia a carência por uma sintonia entre os interesses do homem da cidade e o do campo. O que proporcionou questionamentos acerca da construção e conduções de estratégias para minimizar a precariedade da região. Tal cenário estimulou, em 1996, o surgimento do Consórcio de Desenvolvimento Sustentável da Quarta Colônia (Condesus), formado por nove municípios pertencentes à região, que consorciados constituem uma aliança estratégica em busca do desenvolvimento sustentável da região (Battistella, Erdmann e Wittmann, 2008).

Essa aliança intermunicipal constitui uma associação pública de direito privado e sem fins econômicos, cuja administração é realizada pelos prefeitos dos municípios envolvidos, com o apoio de uma Secretaria Executiva (Quarta Colônia, 2011). Tais predicados caracterizam o consórcio como um caso no qual predomina a existência de uma administração pública.

O presente artigo tem como objetivo descrever, por meio da análise da estrutura de governança, como o Condesus promove a articulação dos municípios da Quarta Colônia 
em prol do desenvolvimento regional. A relevância do estudo se evidencia a partir do momento no qual se observa que a experiência de valorização das potencialidades territoriais da Quarta Colônia leva a questionamentos acerca de como os atores locais cooperam e se mobilizam na busca pela construção e condução de estratégias conjuntas visando minimizar as precariedades da região. E de como ocorreu o processo de criação, planejamento e implementação do Condesus.

A indagação desses preceitos faz com que o Condesus seja escolhido como unidade de estudo, já que representa um caso no qual os atores locais (econômicos, políticos e sociais) se uniram na tentativa de promover o desenvolvimento da Quarta Colônia, a partir da valorização de potencialidades endógenas da região.

Partindo dos pontos destacados, considera-se que o tema do artigo é desenvolvimento regional. Para discutir a temática, realiza-se o estudo de caso de um consórcio intermunicipal (o Condesus), cujo propósito é promover a cooperação entre nove municípios pertencentes a uma mesma região (a Quarta Colônia). Considera-se que conhecer a estrutura de governança do Condesus possibilita entender uma dinâmica original por meio da qual se espera compreender o processo de desenvolvimento regional.

O artigo encontra-se estruturado em sete seções, incluindo a introdução. A seção dois apresenta uma revisão bibliográfica acerca do tema desenvolvimento regional e suas relações com o termo governança. A seção três apresenta três metodologias de análise nas quais se procurou basear a coleta de dados e a análise de resultados. A quarta apresenta os procedimentos metodológicos adotados. A quinta discute e analisa os resultados apontados em relação ao estudo de caso. Por fim, a seção seis expõe as considerações finais, enquanto a sétima apresenta referências bibliográficas.

\section{Desenvolvimento regional e governança}

Nesta seção, são apresentados os pressupostos teóricos relacionados ao desenvolvimento regional de sua perspectiva endógena, conforme abordado na pesquisa. Busca-se, também, aproximar o tema ao conceito de governança, visando esclarecer como a compreensão do termo pode facilitar no entendimento da estrutura de funcionamento do Condesus, mediante um plano de governança regional.

O desenvolvimento regional compreende o crescente esforço das sociedades locais na formulação de políticas territoriais. O que ocorre com o intuito de discutir questões que incluam alterações da composição da sociedade e a alocação de recursos pelos diferentes setores da economia, de forma a melhorar os indicadores de bem-estar econômico e social (pobreza, desemprego, desigualdade, condições de saúde, alimentação, educação e moradia) (Vasconcellos e Garcia, 1998).

Nesses preceitos, compreende-se o desenvolvimento regional como um processo de "mudança social sustentada que tem como finalidade última o progresso permanente da região, da comunidade regional como um todo e de cada indivíduo residente nela" (Boisier, 
1996:33). O mesmo resulta de um crescente esforço das sociedades locais na formulação de políticas territoriais com o intuito de discutir as questões centrais da complexidade contemporânea capazes de tornar a região o sujeito de seu próprio processo de desenvolvimento (Dallabrida, 2000).

Ampliando a discussão, Scott e Storper (2003) ponderam que o processo de desenvolvimento regional envolve uma discussão a respeito de fatores endógenos e exógenos. Sobre esse debate, Leydesdorff, Cooke e Olazaran (2002) destacam a dificuldade de promover o desenvolvimento por meio da atração de investimentos externos. Panorama que levou, a partir da década de 1990, à consolidação de uma concepção que visa envolver os atores regionais, na busca pela superação dos problemas de uma perspectiva endógena.

Com base nesses argumentos, considera-se que o desenvolvimento regional, de uma perspectiva endógena, pode ser observado no caso do Condesus (unidade de análise do estudo), pois o mesmo busca promover a articulação dos municípios pertencentes à Quarta Colônia, a partir das potencialidades internas da região.

Ampliando a discussão acerca do desenvolvimento regional de uma perspectiva endógena, Tapia (2005) ressalta que o sucesso desse processo dependente da articulação de forças do próprio território. Para Boisier (1996), o mesmo deriva do envolvimento direto dos agentes regionais (econômicos, sociais e políticos) na concepção e execução de um projeto próprio de desenvolvimento endógeno.

Por sua vez, Vázquez Barquero (2001) destaca que, no processo de desenvolvimento endógeno, a região passa a ser um agente de transformação e não um suporte dos recursos e atividades econômicas, uma vez que há interação entre empresas e os demais atores, que se organizam para desenvolver a economia e a sociedade. De acordo com esse pensamento, o ponto de partida para uma comunidade territorial reside no conjunto e no inter-relacionamento entre os recursos (econômicos, humanos, institucionais e culturais) formadores de seu próprio potencial de desenvolvimento.

Partilhando do mesmo pensamento, Sotarauta (2005) descreve que o processo de desenvolvimento regional perpassa por uma agenda de mobilização de recursos e atores promotores (instituições, lideranças sociais, organizações) que proporcionem a aprendizagem e troca de conhecimento. Sob esse ponto de vista, Vázquez Barquero (2001) considera que no desenvolvimento endógeno são os atores locais que, ao adotarem estratégias a partir do potencial de desenvolvimento existente em seu território, controlam o processo de transformação econômica e social visando aumentar o bem-estar da sociedade.

De forma complementar, Normann (2012) salienta que o desenvolvimento endógeno deve contemplar preceitos como a inovação e processos de colaboração entre os setores sociais de uma determinada localidade. Tal conjuntura geralmente é permeada pelo surgimento de lideranças locais oriundas de uma base democrática.

A partir das considerações expostas, pondera-se que a articulação dos diversos atores representativos de uma localidade é fundamental para o desenvolvimento. Esses são representados pela sociedade civil, as organizações não governamentais, as instituições privadas e 
o próprio governo. Nesse processo, cada um dos envolvidos tem seu papel para contribuir com o desenvolvimento regional (Buarque, 2006).

Ressaltada a importância da participação ativa dos atores locais para o desenvolvimento endógeno, Coe e colaboradores (2004) destacam que tal concepção envolve aspectos de governança, como forma de viabilizar o inter-relacionamento. Sobretudo para que seja possível contemplar os pressupostos ressaltados por Vázquez Barquero (2001), Sotarauta (2005), Buarque (2006) e Normann (2012). No presente estudo, remete-se à governança como o termo utilizado por Willianson (1996), segundo o qual as decisões tomadas no âmbito de uma organização estão diretamente relacionadas ao seu ambiente institucional.

Sob esse entendimento, Bobbio (2005) aponta que governança se baseia em acordos e contratos negociados junto a uma multiplicidade de atores. Partilhando da mesma visão, Moreiras, Tambosi Filho e Garcia (2012) a compreendem como o conjunto de processos, culturas, políticas, normas e leis que regulam o modo como uma relação interorganizacional é administrada. Enquanto Suzigan, Garcia e Furtado (2007) relacionam o termo à capacidade de coordenação que agentes (empresas, organizações, instituições) exercem sobre as interrelações produtivas, comerciais, tecnológicas e outras, influenciando diretamente o desenvolvimento de um arranjo local.

Nesses preceitos, Storper e Harrison (1991) salientam que a governança é estruturada pelas relações de cooperação existentes, pelo grau de hierarquia, liderança e comando presente entre os participantes do sistema. Enquanto Gilpin (2002) ressalta que a mesma resulta de redes formadas por organizações públicas e privadas em um nível regional, nacional ou internacional, que contêm em si uma função social. Contexto no qual o governo passa a atuar mais como um mediador num processo de negociação política.

De forma mais aprofundada, Humphrey e Schmitz (2000) apontam para as ações de governança visando à criação de sistemas voltados à promoção do desenvolvimento dos produtores locais, centros de prestação de serviços tecnológicos e associações/agências governamentais voltadas para este fim. Abordagem que se aproxima do propósito do presente estudo.

Mais especificamente, no que diz respeito às associações e agências locais de desenvolvimento, Humphrey e Schmitz (2000) apontam que tais instituições atuam como elementos viabilizadores do processo de desenvolvimento regional por meio de ações de fomento à competitividade e de promoção do conjunto das empresas.

A partir dos pressupostos apresentados, pode-se aproximar o termo governança da temática do desenvolvimento regional. Sobre essa aproximação, Albertin (2003:93) salienta que a governança regional "tem sido usada como forma de trabalhar em conjunto e usar o poder coletivo na busca de soluções para problemas comuns". Quando relacionada com seu objetivo, a mesma é definida por ações coletivas de diversos atores na busca do seu desenvolvimento.

Dallabrida (2000:46) ressalta que a governança regional é utilizada para se referir às "iniciativas ou ações que expressam a capacidade de uma sociedade organizada territorialmente, para gerir os assuntos públicos a partir do envolvimento conjunto e cooperativo dos atores sociais, econômicos e institucionais". Para Löffler (2001:212), a mesma tem como ob- 
jeto "a ação conjunta, levada a efeito de forma eficaz, transparente e compartilhada, pelo Estado, pelas empresas e pela sociedade civil, visando uma solução inovadora dos problemas sociais". O que pode criar possibilidades de um desenvolvimento sustentável futuro para todos os participantes.

Para Dallabrida e Becker (2003), as articulações inerentes à governança regional incluem todos os processos que se dão com o objetivo de diagnosticar a realidade, definir prioridades, planejar ações e determinar como os recursos financeiros, materiais e humanos devem ser alocados. Visando a dinamização das potencialidades e a superação dos desafios, a favor do desenvolvimento regional.

Nessa visão, considera-se que a governança regional pode atuar como um mecanismo de "aprofundamento democrático e de desenvolvimento como 'expansão das liberdades', mas também pode ser mecanismo de socialização dos custos e privatização dos ganhos do desenvolvimento" (Rover, 2007:114).

Ressaltada a função da governança regional, alerta-se para o fato de que, junto à elaboração de um plano/programa compartilhado por atores locais, emerge a necessidade de verificar quem realmente participa, toma decisões e se beneficia das ações realizadas. Sobre esse argumento, salienta-se que a existência de um plano de governança não garante que todos os problemas, necessidades e interesses de uma região sejam contemplados, seja pela ausência de recursos ou assimetrias na distribuição de poder (Rover e Henriques, 2006).

A partir das argumentações destacadas, acredita-se que boa parte dos aspectos abordados por Dallabrida (2000), Humphrey e Schmitz (2000), Albertin (2003), Dallabrida e Becker (2003), Rover (2007), Suzigan, Garcia e Furtado (2007) e Moreiras, Tambosi Filho e Garcia (2012) remetem ao Condesus. Dessa forma, considera-se pertinente observar se os pressupostos pelos autores em questão encontram-se presentes na unidade de análise da pesquisa.

Além disso, conforme aspectos apontados por Rover e Henriques (2006), torna-se relevante compreender a estrutura de governança do Condesus como mecanismo mediador das relações e interesses entre os municípios associados a favor do desenvolvimento endógeno.

\section{Metodologias de análise do desenvolvimento regional}

Na presente seção são apresentadas metodologias de análise mostradas pelo Instituto Latinoamericano y del Caribe de Planificación Económica y Social (Ilpes, 1998) e por dois autores que estudam o desenvolvimento regional: Boisier (1996) e Buarque (2006). Esses esquemas/metodologias são vislumbrados como possibilidades de análise de um plano de desenvolvimento regional, uma vez que se observa uma dificuldade em encontrar um consenso a respeito de modelos de análise validados sobre o tema.

Baseando-se na análise dessas três metodologias, se pretende destacar preocupações comuns presentes em projetos regionais exitosos. As características, aspectos e dinâmicas apresentados a seguir serviram como base para a elaboração dos procedimentos metodológicos adotados e a determinação de pontos iniciais a serem observados na análise de resultados. 
Como primeira metodologia de análise a ser destacada, o Ilpes (1998) propõe um processo, baseado em algumas características comuns à maioria dos processos de desenvolvimento que, juntas, poderiam conferir solidez ao processo de desenvolvimento regional. Sob essa forma de análise, a vantagem da gestão local do desenvolvimento reside na capacidade de se conhecer quais são os recursos que estão disponíveis - recursos naturais de cada lugar — e estabelecer um canal direto e dinâmico de interação entre os agentes econômicos e o território.

Aprofundando o estudo sobre o método em destaque, considera-se que o desenvolvimento regional supõe uma série de pré-requisitos ou dinâmicas, tais como: a) compromisso mínimo entre os atores; b) busca de um diálogo entre os representantes políticos e econômicos; e c) superar a incompreensão mútua que aparece na ausência de locais de reunião entre as esferas econômica e social.

Partindo dos pressupostos destacados, o Ilpes (1998) ressalta que o alcance do desenvolvimento regional resulta de um processo que se baseia em um princípio simples: devem-se tomar as medidas necessárias para resolver os problemas e promover potencialidades locais. Este princípio é formulado por meio de diferentes fases, conforme apresenta o quadro 1.

Quadro 1

\section{Fases e conteúdo da dinâmica de desenvolvimento regional}

\begin{tabular}{|ll|}
\hline I. Coleta de dados, análise e diagnóstico: informação & $\begin{array}{l}\text { Proporciona o conhecimento da capacidade de desenvolvimento, } \\
\text { as oportunidades e potencialidades, como os recursos disponíveis } \\
\text { para tanto. }\end{array}$ \\
II. Definição de uma estratégia & $\begin{array}{l}\text { Estabelecimento dos objetivos gerais. Decide-se onde e como se } \\
\text { quer chegar. }\end{array}$ \\
III. Elaboração do plano de ação & $\begin{array}{l}\text { Permite pré-avaliar os projetos separadamente, identificar sua } \\
\text { estrutura e estudar sua viabilidade. }\end{array}$ \\
IV. Seleção e gestão de projetos & $\begin{array}{l}\text { Definem-se e selecionam-se os projetos de desenvolvimento. } \\
\text { V. Implementação }\end{array}$ \\
VI. Avaliação & As ideias se convertem em ações práticas. \\
\hline
\end{tabular}

Fonte: Elaborado pelos autores, adaptado do Ilpes (1998).

A observação das considerações e características apresentadas pela metodologia de processo de desenvolvimento regional proposta pelo Ilpes (1998), especialmente no que diz respeito às fases do planejamento destacadas pelo quadro 1 , permite realizar um paralelo com a metodologia de planejamento proposta por Buarque (2006), que divide o processo de planejamento em quatro etapas sequenciais e interligadas entre si. Estas quatro etapas do planejamento, que, segundo o autor, podem possibilitar o desenvolvimento regional, são expostas a seguir. 


\section{a. Conhecimento da realidade ou diagnóstico:}

a.1. Delimitação do objeto: delimitação da região que se pretende planejar;

a.2. Diagnóstico: auxilia na compreensão da realidade atual da região e os fatores em maturação;

a.3. Prognóstico: busca antecipar possíveis desdobramentos futuros da realidade.

\section{b. Tomada de decisões:}

b.1. Visão de futuro: quando a sociedade define aonde se pretende chegar com a implementação de um plano, o que se define por meio de uma descrição quantitativa e qualitativa da realidade futura. Segundo o autor, a visão de futuro divide-se em:

i. Futuro desejado: estado futuro desejado pela sociedade atemporal e livre de restrições, sinalizando para uma imagem objetivo a longo prazo que serve de referência para as decisões estratégicas;

ii. Objetivos: que serão perseguidos pelo plano de desenvolvimento;

iii. Metas: representam a quantificação dos objetivos, explicando os resultados quantificáveis pretendidos e que podem ser gerados com estratégia ou com plano em determinados prazos.

b.2. Formulação das opções estratégicas: indicam onde devem ser concentradas, de modo a mostrar o caminho geral a ser seguido e organizar a sociedade em torno dos eixos de atuação definidos. Esta etapa deve resultar de uma análise da relação dos problemas e potencialidades endógenas com as oportunidades e ameaças exógenas;

b.3. Elaboração dos programas e projetos: consiste na desagregação das opções estratégicas em programas, políticas e projetos específicos por outros setores ou dimensões da realidade;

b.4. Definição dos instrumentos: momento no qual devem ser definidos e viabilizados instrumentos (meios financeiros, legais, organizacionais, institucionais), que permitirão a execução do plano;

b.5. Formulação do modelo de gestão: é a definição da forma como a sociedade e o Estado (setor público) devem se organizar para a implementação das ações, da gestão dos instrumentos e programas, e para avaliação dos seus resultados.

b.6. Construção da adesão e sustentabilidade políticas: significa discutir com a sociedade o plano e divulgá-lo.

\section{c. Execução do plano:}

c.1. Momento no qual se coloca em prática o planejamento elaborado durante as etapas a e $b$. 


\section{d. Acompanhamento:}

d.1. Controle e avaliação das ações implementadas.

Além dessas quatro etapas do planejamento do desenvolvimento, Buarque (2006) ressalta que, para ter sucesso, um plano precisa responder a questões tais como: a) O que somos? (realidade atual); b) De onde viemos? (história da evolução recente); c) Onde estamos situados? (contexto externo); d) Aonde queremos chegar com o plano de ação? (visão de futuro); e) $\mathrm{O}$ que se deve e pode fazer para chegar aonde queremos?; f) Onde concentrar as ações?; g) Com que meios se podem implementar as ações?; e h) Como se organizar para executar e acompanhar as ações?

Além das metodologias propostas pelo Ilpes (1998) (quadro 1) e por Buarque (2006), Boisier (1996) sugere o hexágono de desenvolvimento regional como uma metodologia capaz de articular inteligentemente seis vértices. O autor em questão defende o pensamento de que o desenvolvimento de um território organizado depende da existência, da articulação e das condições de manejo de seis elementos, que normalmente estão presentes em qualquer território organizado: a) atores, b) instituições, c) cultura, d) procedimentos, e) recursos, e f) entorno; conforme resume o quadro 2 .

\section{Hexágono do desenvolvimento regional}

\begin{tabular}{|c|c|}
\hline Elementos & Descrição \\
\hline Atores & $\begin{array}{l}\text { Consiste em identificá-los por categorias (membros da sociedade civil, agrupamentos empresa- } \\
\text { riais, movimentos sociais e outros) e definir o papel de cada um no plano de desenvolvimento e } \\
\text { governança local. }\end{array}$ \\
\hline Cultura & $\begin{array}{l}\text { Refere-se ao potencial cultural da região no que diz respeito à capacidade de promover a cooperação, } \\
\text { à solidariedade, à autorreferência e à identificação da sociedade com o próprio território. }\end{array}$ \\
\hline Recursos & $\begin{array}{l}\text { Consiste em definir quais os recursos que serão trabalhados pelo plano de desenvolvimento (hu- } \\
\text { manos, financeiros, materiais e/ou psicossociais). }\end{array}$ \\
\hline Instituições & $\begin{array}{l}\text { Consiste no exame do ambiente institucional da região e na identificação de quais instituições } \\
\text { exercem influência e poder na governança local. }\end{array}$ \\
\hline Procedimentos & $\begin{array}{l}\text { Refere-se à natureza de gestão do governo territorial, sendo importante destacar o conjunto de ações } \\
\text { que representam o exercício da autoridade, a capacidade de liderança e a tomada de decisões de } \\
\text { curto e longo alcance. }\end{array}$ \\
\hline Entorno & $\begin{array}{l}\text { Relaciona-se com tudo o que é externo à região ou à província. É o meio externo, configurado pela } \\
\text { multiplicidade de organismos, sobre os quais não se tem controle, mas com os quais a região como } \\
\text { um todo se articula necessariamente. }\end{array}$ \\
\hline
\end{tabular}

Fonte: Elaborado pelos autores, a partir de Boisier (1996).

A partir das análises dos elementos comuns ao desenvolvimento regional apresentados por Boisier (1996), Ilpes (1998) e Buarque (2006) pôde-se conhecer a trajetória e aspectos que precisam ser considerados. 
Tais aspectos são evidenciados quando se procura estudar a dinâmica do processo de desenvolvimento regional, pois permitem a sustentação das análises realizadas a respeito do consórcio, conforme mostra a figura 1.

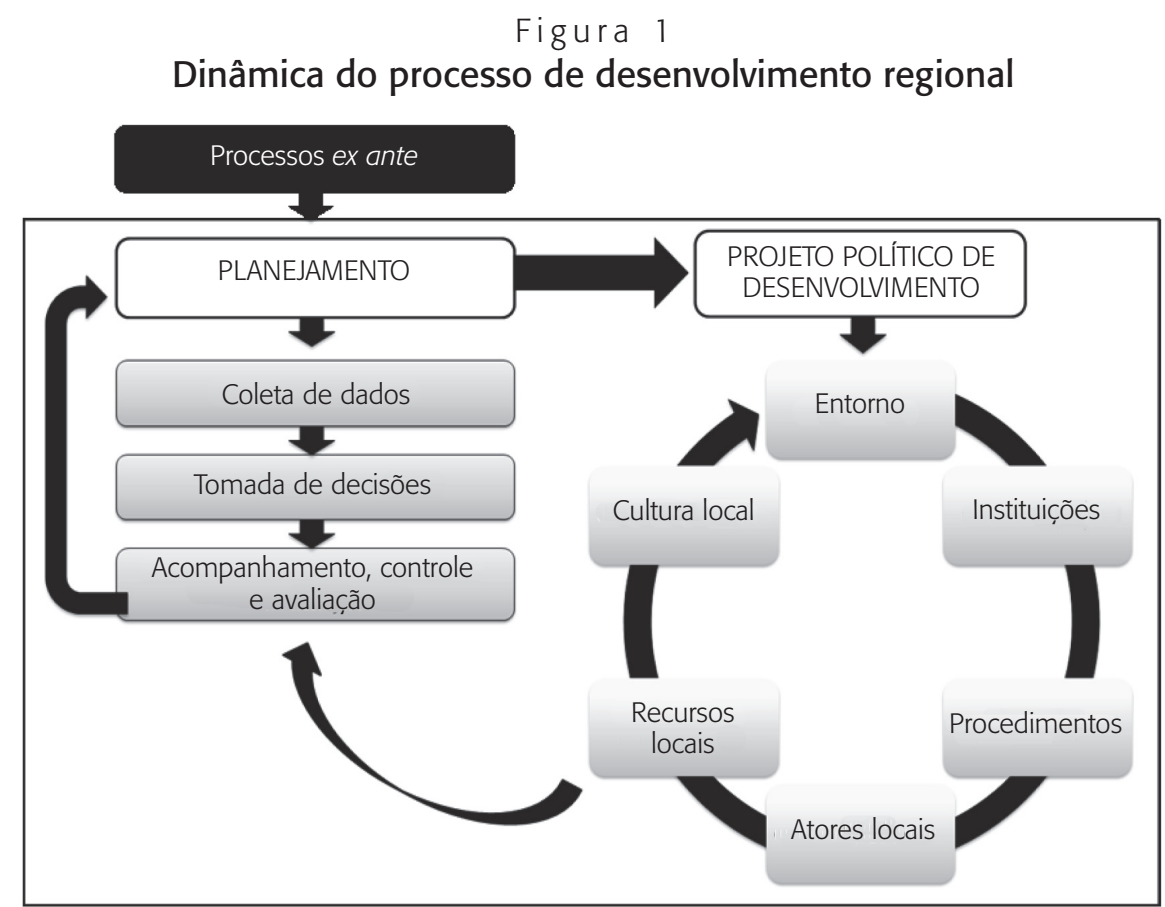

Fonte: Elaborado pelos autores, a partir de Boisier (1996), Ilpes (1998), Buarque (2006) e dos dados coletados.

A dinâmica apresentada pela figura 1 sistematiza que o processo através do qual se pretende analisar o desenvolvimento regional e governança existente no Condesus, dividise em duas etapas interdependentes (planejamento e projeto político de desenvolvimento). Salienta-se que essas etapas são originárias dos processos ex ante ao seu surgimento, os quais envolvem precedentes históricos que levaram à sua criação.

De acordo com a figura 1, a primeira etapa representa o momento no qual o planejamento regional é elaborado e orienta as ações de governança territorial. Nesse momento, são percorridas as fases de coleta de dados (delimitação da região/território, elaboração de diagnóstico e prognóstico); tomada de decisões (formulação de estratégias, definição de instrumentos burocrático-legais, e adesão e diálogo com a sociedade); e acompanhamento, controle e avaliação (resultados alcançados e impasses/obstáculos encontrados).

Verifica-se que planejamento origina o projeto político de desenvolvimento, que constitui a segunda etapa dinâmica regional, na qual é levada em conta a relação existente entre o consórcio e: o entorno (elementos externos à região, mas que a influenciam direta ou indi- 
retamente), a cultura (cooperação, identificação e reconhecimento por parte da sociedade), as instituições (públicas e privadas locais), os recursos (financeiros, humanos e sociais), os procedimentos (gestão, autoridade, liderança, tomada de decisões e procedimentos administrativos) e os atores (membros da sociedade civil, agrupamentos empresariais e movimentos sociais da região).

Ao dimensionar a compreensão dessa dinâmica, torna-se possível alcançar o objetivo principal proposto pelo estudo, que se delineia por meio da proposta de analisar a estrutura de governança existente no Condesus e como o consórcio proporciona a articulação dos municípios da Quarta Colônia em prol do desenvolvimento regional.

\section{Método de estudo}

Esta seção apresenta a estrutura metodológica utilizada que permitiu a operacionalização da pesquisa e encontra-se dividida em: tipo e delimitação da pesquisa; técnicas e instrumentos de coleta de dados; e tratamento, análise e interpretação dos dados.

\subsection{Delimitação da pesquisa}

O estudo constitui-se em uma pesquisa qualitativa, de natureza exploratória descritiva e com o delineamento de estudo de caso. Esta opção decorre do fato de se pretender realizar uma análise compreensiva do processo de governança no contexto de um consórcio intermunicipal (o Condesus). Segundo Minayo (1994), é o método qualitativo que melhor permite responder a esta questão.

A pesquisa qualitativa apresenta características como: tem o ambiente natural como fonte direta de dados; o pesquisador como instrumento fundamental de coleta de dados; utilização de procedimentos descritivos da realidade estudada; busca do significado das situações para as pessoas e os efeitos sobre as suas vidas; preocupação com o processo e não simplesmente com os resultados e o produto; e privilégios ao enfoque indutivo na análise dos dados (Triviños, 1987).

$\mathrm{O}$ delineamento da pesquisa como um estudo de caso se deve à possibilidade de compreender um fenômeno social complexo por meio de um método que permitiu uma investigação que possibilitou preservar as características holísticas e significativas dos acontecimentos da vida real (ciclo de vida dos indivíduos, processos organizacionais e administrativos, mudanças ocorridas em regiões urbanas, relações internacionais e a maturação de setores econômicos) (Yin, 2005).

Essas características são inerentes ao Condesus - unidade de análise da presente pesquisa -, que representa uma dinâmica original de um consórcio que visa promover a cooperação intermunicipal, sob a forma de associação pública de direito privado, através da qual se 
espera compreender o processo de desenvolvimento regional. Casos semelhantes a esse são pouco recorrentes na literatura.

Tais premissas possibilitaram a seleção do delineamento do estudo de caso, pois este método se diferencia devido à sua capacidade de lidar com uma ampla variedade de evidências, como documentos e entrevistas com as pessoas nele envolvidas (Yin, 2005).

\subsection{Fontes da pesquisa}

A presente pesquisa foi realizada em duas etapas subsequentes, sendo a primeira uma pesquisa documental e bibliográfica e a segunda a realização de entrevistas semiestruturadas junto aos grupos de atores (gestores) que integram a estrutura administrativa do caso.

No que se refere à pesquisa documental e bibliográfica, Yin (2005) destaca que, para os estudos de caso, o uso mais importante de documentos é corroborar e valorizar as evidências oriundas de outras fontes, o que permite que sejam feitas inferências a partir de documentos. As inferências devem ser tratadas somente como indícios que valem a pena ser investigados mais a fundo, passíveis de ser falseadas em pesquisas futuras. Destacada a importância dessa etapa, para a presente pesquisa foram consultados, além de materiais bibliográficos: sites da internet, livros, estatutos, relatórios e materiais técnicos disponibilizados pelo consórcio que contêm informações históricas e atuais sobre o caso em estudo.

Posteriormente, na segunda etapa da pesquisa foram realizadas entrevistas semiestruturadas, que, segundo Yin (2005:116), constituem "uma das mais importantes fontes de informações para um estudo de caso". Esse procedimento foi aplicado ao conjunto de atores formais que integram o Condesus, separados em dois grupos, cuja divisão, sintetizada pelo quadro 3, foi estabelecida a partir da estrutura de cargos que compõe o consórcio.

Quadro 3

Grupos de atores (gestores) entrevistados durante a pesquisa

\begin{tabular}{|ll|}
\hline \multicolumn{1}{|c|}{ Grupos } & \multicolumn{1}{c|}{ Descrição } \\
\hline Secretaria Executiva (G1) & Secretário executivo do Condesus \\
Conselho de Prefeitos (G2) & Prefeitos dos nove municípios integrantes do Condesus \\
\hline
\end{tabular}

Fonte: Elaborado pelos autores.

As entrevistas possibilitaram acesso ao conhecimento e ao contexto das pessoas proporcionando uma maior profundidade dos elementos a serem coletados, o que foi feito por meio da elaboração de um roteiro com perguntas preestabelecidas. O roteiro serve, além de coletar as informações básicas, como um meio para o pesquisador se organizar para o processo de interação com o informante, e durante a realização das mesmas foram feitas adequações pertinentes que não foram inicialmente previstas (Lakatos e Marconi, 1992). 
Destaca-se que, para a condução das entrevistas, foram considerados aspectos ressaltados por Gil (2009), tais como: preparação do roteiro de entrevista, estabelecimento do contato inicial, formulação das perguntas, estímulo a respostas em profundidade, registro das respostas e conclusão da entrevista.

O protocolo de entrevistas foi dividido em cinco blocos. Os primeiros quatro blocos buscaram identificar a etapa de planejamento regional que, segundo os pressupostos teóricos apresentados por Ilpes (1998) e Buarque (2006), deve orientar as ações de governança territorial, que ocorrerão nos seguintes momentos: coleta de dados (delimitação da região/território, elaboração de diagnóstico e prognóstico); tomada de decisões (elaboração da visão de futuro, demarcação de estratégias, programas e projetos, definição de instrumentos e formulação de modelos de gestão); execução (momento no qual aquilo que foi planejado é colocado em ação); e avaliação (reflexão sobre os impactos e resultados das ações executadas).

Finalmente, o quinto bloco foi objeto da averiguação da pesquisa em relação à dinâmica existente entre as seis variáveis apresentadas por Boisier (1996): entorno, cultura, instituições, recursos, procedimentos e atores, que juntas caracterizam o projeto político de desenvolvimento resultante do planejamento regional elaborado.

Com relação ao tempo de duração das entrevistas, ressalta-se que a realizada com o secretário executivo do Condesus (G1) durou 2h30min, enquanto as realizadas junto aos nove prefeitos membros do Conselho de Prefeitos (G2) tiveram em média 45 minutos de duração, cada uma. Salienta-se que a entrevista com o G1 teve maior duração em relação às demais pelo fato de o secretário executivo estar diretamente envolvido desde os momentos precedentes à origem do consórcio até o momento atual. No mais, considera-se importante frisar que nenhum dos autores do artigo possui qualquer tipo de envolvimento com o caso em estudo.

\subsection{Análise e interpretação dos dados}

Após a realização das entrevistas semiestruturadas e coleta das fontes secundárias, foram realizadas a tabulação e a análise de dados. Nesse momento, as entrevistas foram gravadas e transcritas, o que facilitou a categorização das informações e a identificação de elementos necessários para a análise.

O tratamento dos dados qualitativos foi feito seguindo o método da análise de conteúdo (Bardin, 1977), com o auxílio do software NVivo 8.0, com o qual foi possível codificar, filtrar, fazer buscas, questionar e categorizar os dados para responder ao problema de investigação.

A análise de conteúdo tem por objetivo identificar o que foi relatado sobre o tema em estudo. O método de análise de conteúdo possibilitou ao pesquisador definir um conjunto de elementos que, por meio de procedimentos sistemáticos e objetivos de descrição do conteúdo das mensagens, geraram indicadores que permitiram a inferência de conhecimentos relativos às condições de produção destas mensagens (Bardin, 1977).

O método de análise de conteúdo seguiu as indicações de Bardin (1977), as quais descrevem que se devem percorrer três principais etapas, conforme descrito a seguir: 
a) Pré-análise: momento no qual devem ser definidos e preparados os documentos/materiais a serem analisados, formuladas as hipóteses e/ou objetivos, e identificados os indicadores que irão fundamentar a interpretação final;

b) A exploração do material: nessa etapa os materiais devem ser codificados, recortados, classificados e categorizados; e

c) Tratamento, inferência e interpretação dos dados.

Os dados qualitativos do presente estudo foram obtidos e analisados na seguinte ordem: a) revisão bibliográfica sobre os temas que envolvem o caso estudado; b) pesquisa de fontes secundárias; c) definição dos blocos integrantes do protocolo de entrevistas; d) elaboração do roteiro de entrevistas; e) agendamento das entrevistas; f) realização da pesquisa de campo; g) exploração do material coletado; h) tratamento, inferência e interpretação dos dados; e i) análise dos resultados.

\section{Discussão e análise dos resultados referentes ao Condesus}

Nesta seção são apresentados os resultados obtidos pela pesquisa, que viabilizaram que fosse alcançado o objetivo de descrever, através da análise da estrutura de governança, como o Condesus promove a articulação dos municípios da Quarta Colônia em prol do desenvolvimento regional.

No entanto, ressalta-se que, durante a realização e análise das entrevistas, identificouse que seria insuficiente analisar a estrutura de governança do Condesus sem que antes se buscasse conhecer o contexto de surgimento do mesmo. Percebe-se que se torna importante elencar a compreensão dos momentos que precederam e influenciaram diretamente a origem do consórcio, ou seja, como destaca Yin (2005), há a necessidade de relevar fatos que o tornam um fenômeno contemporâneo dentro de seu contexto da vida real e caracterizam o estudo como um estudo de caso. O que foi feito no primeiro momento da discussão dos resultados, para que, em seguida, fossem feitas as demais análises, visando atingir ao objetivo proposto.

\subsection{Processos ex ante a formação do Condesus}

A partir das considerações apresentadas pelo secretário executivo do Condesus e das fontes secundárias observadas, procurou-se compreender os processos ex ante ao planejamento e consolidação do consórcio, subdivididos em duas etapas: a) processos ex ante: precedentes; e b) processos ex ante: dificuldades.

No que diz respeito aos precedentes, por meio dos dados observados, verificou-se que houve momentos preponderantes que levaram ao surgimento do consórcio e que, de certa forma, influenciaram diretamente a maneira pela qual se configura a estrutura de governança do Condesus, identificados na figura 2, em ordem cronológica: 
Figura 2

Processos ex ante: precedentes à criação do Condesus

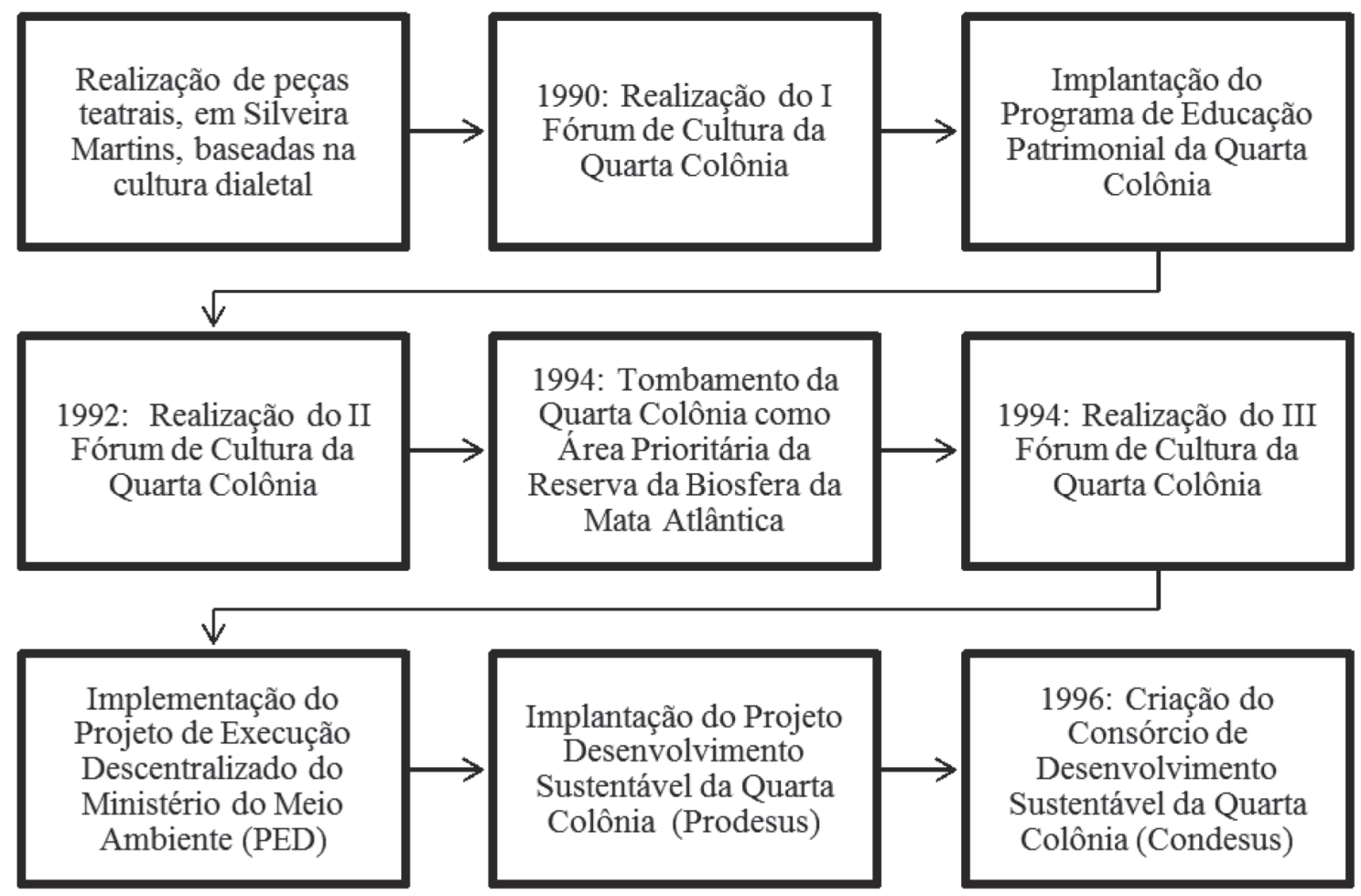

Fonte: Elaborado pelos autores, a partir dos dados coletados.

Além dos precedentes, outros pontos importantes e influentes foram observados para a análise da atual estrutura de governança do Condesus. Tais pontos se referem aos aspectos que caracterizam dificuldades enfrentadas pelos agentes regionais durante os momentos ex ante à criação do consórcio. Seguindo o mesmo critério adotado para a análise dos precedentes, foram analisados pontos evidenciados especialmente pelo secretário executivo, o que se deve ao fato de ele ser, dentro do universo dos entrevistados, aquele que acompanhou o processo de surgimento do Condesus desde o começo.

Observou-se por meio da análise das entrevistas realizadas que houve dificuldades enfrentadas para que o consórcio fosse implementado e que as estratégias propostas pelo mesmo fossem postas em prática. Dentre os empecilhos, destacaram-se: a) problemas conjunturais relacionados à superficialidade dos projetos de futuro para os municípios da região; b) carência por planos que buscassem a transformação e a valorização da realidade e cultura local; c) resistências ideológicas em relação à integração regional; d) fragilidade das relações locais; e) necessidade de construção de uma identidade regional; f) lutas políticas nos e entre os municípios da região; g) entraves burocrático-legais; h) cobrança por resultados que se refle- 
tissem nas atividades econômicas; e i) deficiência por programas de governo que visassem o desenvolvimento a médio e longo prazo (quadro 4).

$$
\text { Quadro } 4
$$

Processos ex ante: elementos dificultadores ao surgimento do Condesus

\begin{tabular}{|l|}
\hline \multicolumn{1}{|c|}{ Processos ex ante } \\
\hline Inexistência de um projeto futuro \\
Superficialidade e fragmentação das ações propostas \\
Desvalorização da realidade e da cultura local \\
Resistência à visão regional \\
Fragilidade das relações locais e regionais \\
Lutas políticas na região \\
Aspectos burocrático-legais \\
Período eleitoral \\
Ausência de cooperativismo \\
Visão economicista \\
Imediatismo
\end{tabular}

Fonte: Elaborado pelos autores, a partir dos dados coletados.

Os elementos destacados no quadro 4 identificaram obstáculos enfrentados pelos agentes regionais durante a criação do Condesus, especialmente no que diz respeito ao empenho em prol da construção de uma identidade regional, valorização da cultura local, elaboração de um projeto de futuro e surgimento de um sentimento de cooperação entre os atores locais. Suprir essas carências é apontado por autores como Boisier (1996), Ilpes (1998), Vázquez Barquero (2001), Sotarauta (2005), Tapia (2005), Buarque (2006) e Normann (2012) como alguns dos pontos de partida para que se possa propiciar o desenvolvimento regional.

\subsection{Condesus e sua governança}

O Condesus é o resultado de um processo histórico anterior (processos ex ante) que contemplou diversos momentos que promoveram o resgate da identidade local, a partir dos Fóruns de Cultura da Quarta Colônia e, consequentemente, da elaboração de projetos de âmbito regional (caso do Prodesus), propiciando o surgimento de uma visão regional, baseada no cooperativismo e na valorização da cultura regional.

Atualmente, o consórcio constitui uma associação pública de direito privado que tem suas ações delimitadas na região da Quarta Colônia (Agudo, Dona Francisca, Faxinal do Soturno, Ivorá, Nova Palma, Pinhal Grande, Restinga Seca, São João do Polêsine e Silveira Martins). O consórcio possui sua estrutura administrativa composta por: a) Presidência (presi- 
dente e vice-presidente); b) Conselho de Prefeitos; e c) Secretaria Executiva, conforme mostra a figura 3.

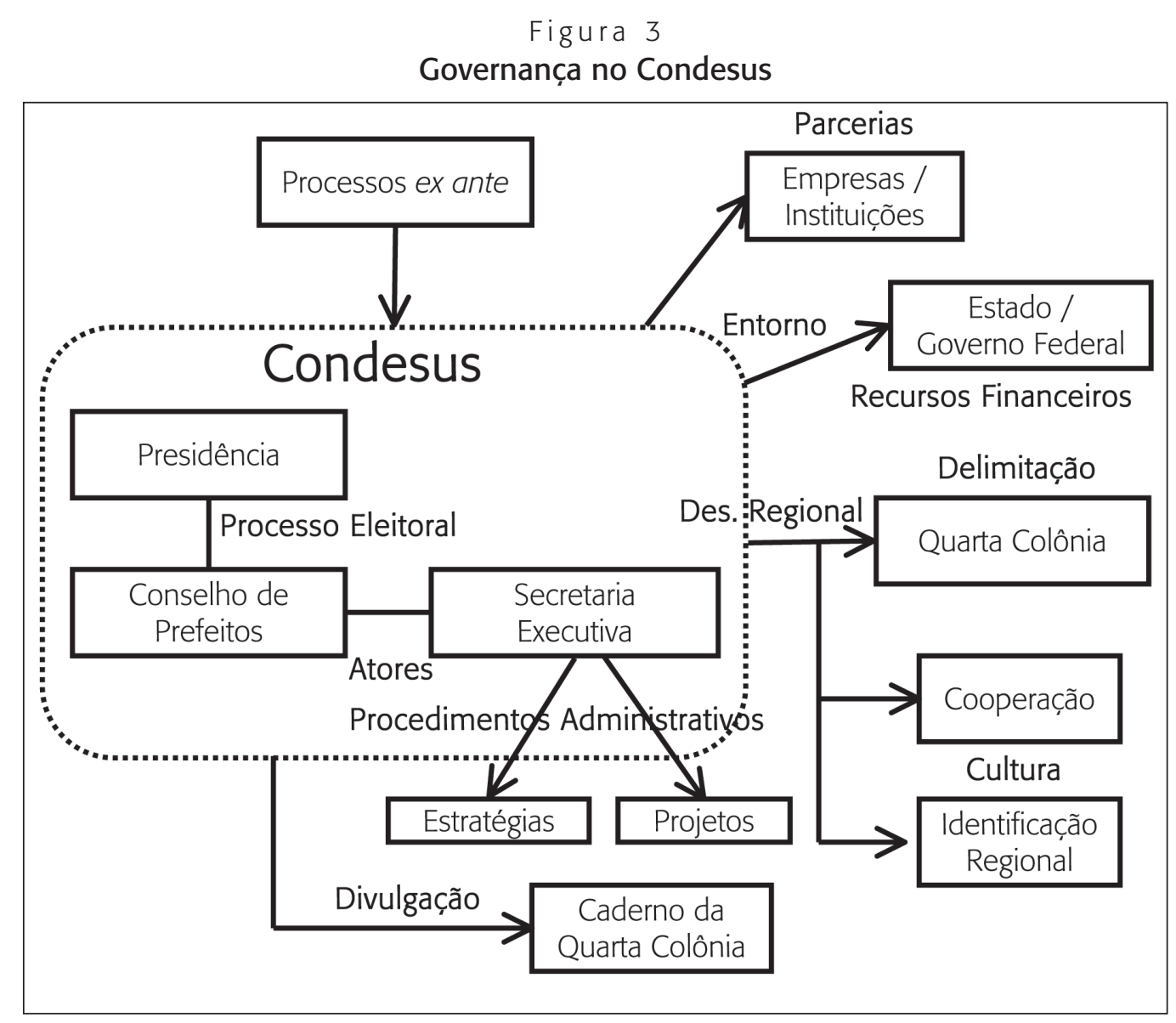

Fonte: Elaborado pelos autores, a partir dos dados coletados.

Sobre a estrutura administrativa do Condesus, cujo Conselho é composto pelos prefeitos dos municípios da Quarta Colônia, e a eleição da presidência ocorrendo a cada dois anos, a Secretaria Executiva é composta por um secretário executivo (contratado como cargo de confiança) e por uma secretária (empossada via concurso público), e estes representam os únicos atores que possuem cargos de poder, autoridade e liderança dentro do consórcio.

A Secretaria Executiva do Condesus, além dos procedimentos administrativos, é o setor responsável pela elaboração de estratégias e proposição de projetos, que são submetidos à aprovação por parte do Conselho de Prefeitos e da Presidência. Os projetos e ações desenvolvidos pelo consórcio, e seus respectivos resultados, são divulgados para a sociedade por meio do Caderno da Quarta Colônia, vinculado junto à Zero Hora e em rádios locais. 
Para tomada de decisões, o Condesus diagnosticou as principais potencialidades da região, tais como a agricultura/agroindústria familiar, o turismo, o patrimônio e a proximidade cultural e geográfica dos municípios integrantes, o que favorece a busca por ações conjuntas visando o desenvolvimento regional da Quarta Colônia.

Devido ao foco das ações desenvolvimentistas na Quarta Colônia, nota-se que o consórcio não possui projetos e ações voltadas para o desenvolvimento das comunidades do entorno (distritos e municípios vizinhos que fazem limites com os integrantes da região), estando o relacionamento com esse ambiente externo restrito a parcerias com instituições e empresas, e à busca de recursos financeiros junto a órgãos do estado e do governo federal.

Nota-se, também, uma fragilidade do consórcio no que diz respeito ao relacionamento do mesmo com as comunidades dos municípios da região, que não participam da elaboração dos projetos propostos pelo Condesus e, consequentemente, não reconhecem a importância deste para o desenvolvimento da Quarta Colônia.

Nesses preceitos, conforme resume a primeira coluna do quadro 5, infere-se que o Condesus proporciona a articulação dos municípios da Quarta Colônia em prol do desenvolvimento regional a partir do momento no qual: a) promove o surgimento de uma identidade regional, baseada no cooperativismo entre os agentes envolvidos; b) desenvolve, mediante projetos elaborados e propostos pela Secretaria Executiva, ações que visam beneficiar e desenvolver a todos os seus integrantes; c) restringe os interesses individuais determinantes para a tomada de decisões locais e regionais; d) favorece o desenvolvimento regional a partir da valorização das potencialidades locais; e) possibilitou o fortalecimento da "marca" Quarta Colônia; e f) viabiliza a estruturação de um plano de desenvolvimento, baseado nos interesses regionais.

Quadro 5

Pontos propulsores e restritivos do desenvolvimento relacionado às ações do Condesus, na região da Quarta Colônia

\begin{tabular}{|lc|}
\hline \multicolumn{1}{|c}{ Pontos propulsores do desenvolvimento } & Pontos restritivos do desenvolvimento \\
\hline - Surgimento de identidade regional & - Baixo relacionamento com as comunidades/regiões do \\
- Cooperativismo & entorno \\
- Prioriza ações que beneficiam a todos os integrantes & - Baixa participação de atores econômicos e sociais \\
- Não prioriza os interesses individuais & - Pouco relacionamento entre o consórcio e as instituições \\
- Valorização das potencialidades locais & - Necessidade de qualificação e retenção de recursos \\
- Fortalecimento da "marca" Quarta Colônia & humanos \\
- Plano de desenvolvimento, baseado nos interesses & - Carência por obras de infraestrutura relacionada à \\
regionais & recepção de turistas \\
\hline
\end{tabular}

Fonte: Elaborado pelos autores, a partir dos dados coletados.

No entanto, observa-se na segunda coluna do quadro 5 que, mesmo diante dos aspectos positivos ressaltados, o Condesus carece de melhorias no que diz respeito a aspectos tais 
como: a) aprofundamento das relações com as comunidades e regiões do entorno; b) participação dos atores econômicos e sociais da região, tanto na elaboração dos projetos, quanto na tomada de decisões; c) relacionamento entre o consórcio e o apoio institucional do qual ele faz parte; d) possibilidade de o consórcio realizar planos visando qualificar os recursos humanos da região e desenvolver meios capazes de reter essa mão de obra nos municípios integrantes; e e) melhoria de infraestrutura local, especialmente relacionada à recepção de visitantes nos municípios.

\section{Considerações finais}

Diante dos objetivos estabelecidos, observou-se que o Condesus constitui uma associação pública de direito privado, que conta com uma estrutura administrativa composta pela a) Presidência; b) Conselho de Prefeitos e c) Secretaria Executiva. O consórcio tem seus projetos focados no desenvolvimento da Quarta Colônia, com suas ações determinadas pelo cooperativismo envolvendo os nove municípios da região, conforme ilustra a figura 3.

As principais estratégias e projetos propostos pelo Condesus são elaborados pela Secretaria Executiva, que também é a responsável pelos procedimentos administrativos dentro do consórcio, executando funções tais como manejo orçamentário, gestão de projetos e relações públicas. Como principais fontes de obtenção de recursos financeiros por parte do consócio, destacam-se as mensalidades pagas pelos associados e os recursos adquiridos junto a órgãos federais e estaduais. Tais observações fornecem as bases para que o objetivo principal da pesquisa tenha sido alcançado.

Ao se conhecerem os relatos sobre os momentos históricos que precederam a criação do Condesus (figura 2), observou-se que o consórcio é resultante de seguidas ações que tiveram como interesse principal o surgimento de um sentimento de valorização da cultura local e, consequentemente, a conscientização dos envolvidos sobre a necessidade de se estabelecer ações cooperativas que tenham como objetivo beneficiar a região como um todo. Conforme destacado por Boisier (1996), Ilpes (1998), Vázquez Barquero (2001), Sotarauta (2005), Tapia (2005), Buarque (2006) e Normann (2012), a cooperação constitui um elemento central para que se possa obter êxito através de políticas integradoras visando o desenvolvimento regional.

Apesar das dificuldades ex ante enfrentadas decorrentes da ausência de uma visão regional viabilizadora de um projeto de futuro regional e dos impasses/obstáculos vivenciados (quadro 4), nota-se que o consórcio trouxe para a região benefícios, tais como fortalecimento da "marca" local, ascensão do turismo, planejamento regional e realização de obras de infraestrutura (especificamente estradas) (primeira coluna do quadro 5). O alcance desses resultados benéficos só foi possível devido ao fato de o consórcio ter construído entre seus membros uma visão cooperativa e integradora, que favoreceu o surgimento de uma identidade regional e o reconhecimento da região pelas pessoas de fora; resultados estes estreitamente relacionados ao elemento cultura ressaltado por Boisier (1996). 
No entanto, mesmo diante dos resultados positivos destacados em relação ao Condesus, nota-se que o mesmo possui pouco reconhecimento por parte da sociedade e da comunidade local, que não enxerga o consórcio como um elemento viabilizador do desenvolvimento regional (segunda coluna do quadro 5). O que pode ser explicado pela estruturação da governança no mesmo, que restringe a tomada de decisões aos atores políticos, limitando a participação tanto dos atores privados quanto dos sociais nesse processo.

Essa restrição configura um ponto a ser melhorado em relação ao caso, pois conforme ressaltam Boisier (1996), Ilpes (1998), Dallabrida (2000), Vázquez Barquero (2001), Sotarauta (2005), Tapia (2005), Buarque (2006) e Normann (2012), a participação conjunta dos atores públicos, privados e sociais é um dos fatores considerados como essenciais para o desenvolvimento regional. Por outro lado, observando os resultados obtidos por meio do estudo de caso, surge o questionamento: seria possível/viável estabelecer uma estrutura organizacional que permitisse a participação de todos os atores da sociedade? Ou realmente fazse necessário centralizar essas decisões em um determinado grupo de atores em específico, conforme ocorre no Condesus?

Além da deficiência em relação à participação dos atores privados e sociais no consórcio, através dos resultados observa-se que as ações propostas pelo Condesus, em quase a sua totalidade, têm como propósito buscar recursos financeiros junto às esferas estadual e federal. Não sendo possível, no entanto, observar ações que demonstrem e caracterizem, efetivamente, a promoção do desenvolvimento da região através do crescimento econômico, social e cultural, atrelado à melhoria da qualidade de vida nos mesmos, ou seja, do bem-estar econômico e social (pobreza, desemprego, desigualdade, condições de saúde, alimentação, educação e moradia), requisitos destacados com centrais.

Tal consideração traz a necessidade por questionamentos sobre a real capacidade do consórcio em promover o desenvolvimento regional, conforme sugerem os pressupostos teóricos apresentados por autores como Vasconcellos e Garcia (1998) e Oliveira (2002), sendo esse um ponto que fica em aberto para que possa ser investigado em pesquisas futuras.

Como outro ponto negativo, observa-se a necessidade por um melhor relacionamento entre o Condesus e as instituições locais, destacando-se, principalmente, a carência por uma aproximação do consórcio com as câmaras de vereadores dos municípios integrantes (segunda coluna do quadro 5). Esse ponto contraria a teoria apresentada por Boisier (1996), além de autores tais como Dallabrida (2000), Humphrey e Schmitz (2000), Vázquez Barquero (2001), Dallabrida e Becker (2003), Rover (2007), Suzigan, Garcia e Furtado (2007) e Moreiras, Tambosi Filho e Garcia (2012), que salientam as instituições como importantes no que diz respeito ao estabelecimento e controle sobre regras e normas locais.

Ademais, observa-se a necessidade por projetos que busquem desenvolver, em conjunto, as regiões/municípios do entorno, estando o relacionamento com esse ambiente limitado à existência de parcerias com universidades e instituições tais como a Empresa de Assistência Técnica e Extensão Rural (Emater) e o Serviço Brasileiro de Apoio às Micro e Pequenas Empresas (Sebrae) (segunda coluna do quadro 5), sendo essa uma deficiência em relação ao hexágono do desenvolvimento regional apresentado por Boisier (1996). 
Outro ponto relacionado ao hexágono de Boisier (1996) detectado como carente por melhorias diz respeito à necessidade de definição de estratégias que visem qualificar a mão de obra local (especialmente mediante cursos de capacitação continuada) e reter os recursos humanos capacitados na região, inibindo a migração destes para outros centros (segunda coluna do quadro 5).

Além dos aspectos levantados durante a etapa de análise de resultados, outra contribuição relevante relaciona-se ao caráter exploratório do estudo que, através de uma pesquisa baseada em estudos anteriores, propõe uma dinâmica original por meio da qual se espera compreender o processo de desenvolvimento regional (figura 1).

Como limitação da pesquisa, ressalta-se que foi considerada a inclusão de um grupo que envolvesse os atores sociais dos municípios da Quarta Colônia (moradores, representantes de associações de bairro e dos municípios) e outro que abarcasse os atores privados locais (representantes de associações empresariais/comerciais e industriais da região). Porém, durante a realização da pesquisa, observou-se que a inserção desses grupos inviabilizaria a conclusão do trabalho, sendo este ponto uma sugestão para a realização de pesquisas futuras.

Outra sugestão futura compete à possibilidade de replicar a metodologia utilizada em outros casos, na tentativa de se obter resultados que venham a corroborar ou falsear as análises aqui realizadas e, consequentemente, contribuir com o avanço teórico de estudos envolvendo a mesma temática.

\section{Referências}

ALBAGLI, Sarita. Novos espaços de regulação na era da informação e do conhecimento. In: LASTRES, Helena M. M.; ALBAGLI, Sarita (Org.). Informação e globalização na era do conhecimento. Rio de Janeiro: Campus, 1999.

ALBERTIN, Marcos. O processo de governança em arranjos produtivos: o caso da cadeia automotiva do RGS. Tese (doutorado em engenharia de produção) — Universidade Federal do Rio Grande do Sul, Porto Alegre, 2003.

BARDIN, Laurence. Análise de conteúdo. Lisboa: Edições 70, 1977.

BATTISTELLA, Luciana F.; ERDMANN, Rolf H.; WITTMANN, Milton L. A experiência vivida pelo ser-gestor no desenvolvimento regional de um consórcio de municípios. Revista de Administração da UFSM, Santa Maria, v. 1, n. 2, p. 263-274, maio/ago. 2008.

BOBBIO, Luigi. Governance multilivello e democrazia. Rivista delle Politiche Sociali, Roma, n. 2, p. 51-62, 2005.

BOISIER, Sergio. Em busca do esquivo desenvolvimento regional: entre a caixa-preta e o projeto político. Planejamento e Políticas Públicas, Brasília, n. 13, p. 111-147, 1996.

BOISIER, Sergio. Post-scriptum sobre desenvolvimento regional: modelos reais e modelos mentais. Planejamento e Políticas Públicas, Brasília, n. 9, p. 307-343, 1999. 
BUARQUE, Sérgio C. Construindo o desenvolvimento local sustentável: metodologia de planejamento. Rio de Janeiro: Garamond, 2006.

COE, Neil M. et al. 'Globalizing' regional development: a global production networks perspective. Transactions of the Institute of British Geographers, v. 4, n. 29, p. 468-484, 2004.

COOKE, Philip; LEYDESDORFF, Loet. Regional development in the knowledge-based economy: the construction of advantage. The Journal of Technology Transfer, v. 1, n. 31, p. 5-15, 2006.

DALLABRIDA, Valdir R. O desenvolvimento regional: a necessidade de novos paradigmas. Ijuí: Editora Unijuí, 2000.

DALLABRIDA, Valdir R.; BECKER, Dinizar F. Governança territorial: um primeiro passo na construção de uma proposta teórico-metodológica. Desenvolvimento em Questão, Ijuí, ano 1, n. 2, p. 73-98, jul./dez. 2003.

GIL, Antônio C. Como elaborar projetos de pesquisa. 4. ed. 12. reimp. São Paulo: Atlas, 2009.

GILPIN, Robert. A realist perspective on international governance. In: HELD, David; MCGREW, Anthony (Org.). Governing globalization. Cambridge: Polity Press, 2002. p. 237-248.

GOBIERNO VASCO. Plan forestal vasco: 1994-2030. Dpto. Agricultura, 1994.

HUMPRHEY, John; SCHMITZ, Hubert. Governance and upgrading: linking industrial cluster and global value chain research. IDS Working Paper, n. 120. Brighton: Institute of Development Studies, University of Sussex, 2000.

ILPES. Manual de desarrollo local. Santiago: Instituto Latinoamericano y del Caribe de planificación económica y social, 1998.

LAKATOS, Eva M.; MARCONI, Marina de A. Metodologia científica. São Paulo: Atlas, 1992.

LEYDESDORFF, Loet; COOKE, Philip; OLAZARAN, Mikel. Technology transfer in european regions. Journal of Technology Transfer, v. 27, n. 1, p. 5-13, 2002.

LÖFFLER, Elke. Governance: die neue generation von staats-und Verwaltungsmodernisierung. Verwaltung + Management, v. 7, n. 4, p. 212-215, 2001.

LORENZO, Helena C. de; FONSECA, Sergio de A. A promoção do desenvolvimento local apoiada em redes de municípios: a experiência do Consórcio Intermunicipal Central Paulista. Interações, Campo Grande, v. 9, n. 1, p. 55-63, jan./jun. 2008.

MARTINS, Sérgio. R. O. Desenvolvimento local: questões conceituais e metodológicas. Revista Internacional de Desenvolvimento Local. v. 3, n. 5, p. 51-59, set. 2002.

MINAYO, Maria C. de S. Pesquisa social. Petrópolis: Vozes, 1994.

MOREIRAS, Luiz M. F.; TAMBOSI FILHO, Elmo; GARCIA, Fabio. G. Dividendos e informação assimétrica: análise do novo mercado. Revista de Administração - RAUSP, São Paulo, v. 47, n. 4, p. 671-682, out./nov./dez. 2012. 
NORMANN, Roger. Regional leadership: a systemic view. Systemic practice and action research, n. 26, v. 1, p. 23-38, 2012.

OLIVEIRA, Gilson B. de. Uma discussão sobre o conceito de desenvolvimento. Revista FAE, Curitiba, v. 5, n. 2, p. 37-48, maio/ago. 2002.

PIRES, Márcio de S. Construção do modelo endógeno, sistêmico e distintivo de desenvolvimento regional e a sua validação através da elaboração e da aplicação de uma metodologia ao caso do Mercoeste. Tese (doutorado em engenharia de produção) — Universidade Federal de Santa Catarina, Florianópolis, 2001.

QUARTA COLÔNIA. Portal da Região da Quarta Colônia. Disponível em: <www.quartacolonia.com. br/>. Acesso em: 12 jan. 2011.

ROVER, Oscar J. Redes de poder e governança local: análise da gestão político-administrativa em três fóruns de desenvolvimento com atuação na região Oeste de Santa Catarina/Brasil. Tese (doutorado em desenvolvimento rural) — Universidade Federal do Rio Grande do Sul, Porto Alegre, 2007.

ROVER, Oscar J.; HENRIQUES, Maria A. A gestão democrática em debate: o Programa Leader e a sua relação com a sociedade civil local. Revista Crítica de Ciências Sociais, Coimbra, n. 75, p. 117137, out. 2006.

SACHS, Ignacy. Ecodesenvolvimento: crescer sem destruir. São Paulo: Vértice, 1986.

SCOTT, Allen J.; STORPER, Michael. Regions, globalization, development. Regional Studies, v. 6-7, n. 37, p. 549-578, 2003.

SOTARAUTA, Markku. Shared leadership and dynamic capabilities in regional development. In: SAGAN, Iwona; HALKIER, Henrik (Ed.). Regionalism contested: institution, society and governance. Ashgate: Cornwall, 2005. p. 1-21.

STORPER, Michaek; HARRISON, Bennett. Flexibility, hierarchy and regional developments: the changing structure of industrial production systems and their forms of governance in the 1990s. Research Policy, v. 20, n. 5, p. 407-422, 1991.

SUZIGAN, Wilson; GARCIA, Renato; FURTADO, João. Estruturas de governança em arranjos ou sistemas locais de produção. Gestão \& Produção, São Carlos, v. 14, n. 2, p. 425-439, maio/ago. 2007.

TAPIA, Jorge. R. B. Desenvolvimento local, concentração social e governança: a experiência dos pactos territoriais na Itália. São Paulo em Perspectiva, v. 19, n. 1, p. 132-139, jan./mar. 2005.

TRIVIÑOS, Augusto N. S. Pesquisa qualitativa. In: TRIVIÑOS, Augusto N. S. (Ed.). Introdução à pesquisa em ciências sociais: a pesquisa qualitativa em educação. São Paulo: Atlas, 1987. p. 116-173.

VASCONCELLOS, Marco A.; GARCIA, Manuel E. Fundamentos de economia. São Paulo: Saraiva, 1998.

VÁZQUEZ BARQUERO, Antônio. Desenvolvimento endógeno em tempos de globalização. Porto Alegre: Fundação de Economia e Estatística, 2001. 
WILLIAMSON, Olivier E. The mechanisms of governance. Nova York: Oxford University Press, 1996.

XAVIER, Thiago R. Regionalização e desenvolvimento: um estudo de caso de um consórcio intermunicipal. Dissertação (mestrado em administração) — Universidade Federal de Santa Maria, Santa Maria, 2012.

YIN, Robert. Estudo de caso: planejamento e métodos. 3. ed. Porto Alegre: Bookman, 2005.

Thiago Reis Xavier é doutorando e mestre do Programa de Pós-Graduação em Administração da Universidade Federal de Santa Maria (PPGA/UFSM). E-mail: thiago.adm.tur@gmail.com.

Milton Luiz Wittmann é doutor em administração pela Faculdade de Economia e Administração da Universidade de São Paulo (FEA/USP) e professor associado IV da Universidade Federal de Santa Maria (UFSM). E-mail: wittmann@profwittmann.com.

Raoni de Oliveira Inácio é mestre pelo Programa de Pós-Graduação em Administração da Universidade Federal de Santa Maria (PPGA/UFSM). E-mail: raoni06@yahoo.com.br.

Juliana Kern é graduanda do Curso de Administração da Universidade Federal de Santa Maria (UFSM). E-mail: julianakern@ymail.com. 
